A. M. A. K., and Ali, M. A.: Oral therapy in children with cholera: A comparison of sucrose and glucose electrolyte solutions. J. Pediatr., 96: 20 $(1980)$.

20. Sack, R. B., Pierce, N., and Hirschhorn, N.: The current status of oral therapy in the treatment of acute diarrhea illness. Am. J. Clin. Nutr., 31:2251 (1978).

21. Schmidt-Neilsen, B., Schmidt-Neilsen, K., Houpt, T. R., and Jarnum, S. A.: Water balance of the camel. Am. J. Physiol., 185: 185 (1956).

22. Sotos, J. F., Dodge, P. R., Meara, P., and Talbot, N.: Studies in experimental hypertonicity: I. Pathogenesis of the clinical syndrome, biochemical abnormalities and causes of death. Pediatrics, 26: 925 (1960).

23. Zissa, F. and Reeve, E. B.: Erroneous measurement of plasma volume in the rabbit by T-1824. Am. J. Physiol., 194: 522 (1958).
24. The present address of Dr. Philip R. Dodge, Department of Pediatrics, Washington University School of Medicine, 500 South Kingshighway, St. Louis, Missouri 63178.

25. The present address of Dr. Larry K. Pickering, Department of Pediatrics, Program in Infectious Diseases, University of Texas Medical School, 6431 Fannin Street, Houston, Texas, 77030.

26. Requests for reprints should be addressed to: Dr. Gwendolyn R. Hogan, Department of Neurology, Louisiana State University School of Medicine 1501 Kings Highway, Shreveport, Louisiana 71103.

27. Received for publication November 24,1981

28. Accepted for publication July 1, 1983.

\title{
Resistance of the Male Gonad to a High Galactose Diet
}

\author{
Y. T. CHEN, ${ }^{(26)}$ D. R. MATTISON, B. B. BERCU, AND J. D. SCHULMAN
}

Laboratory of Developmental Pharmacology, [Y.T.C.] and the Pregnancy Research Branch [D.R.M., B.B.B.], National Institute of Child Health and Human Development, National Institutes of Health, Bethesda, Maryland and Depatment of Obstetrics and Gynecology [J.D.S.], Pediatrics and Genetics, George Washington University

Washington, D.C., USA

\section{Summary}

Rats were fed a $50 \%$ galactose diet during pregnancy and nursing, and the testes were later examined and hormone levels determined in male offspring. Exposure to galactose for various periods during pregnancy, throughout the entire gestation, or postnatally to nursing mother until pups were 5 wk of age produced no significant differences from control testicular weight, seminiferous tubular diameter, or microscopic appearance of the testis when the offspring became adult (66 or $127 \mathrm{~d}$ ). Serum leuteinizing hormone, follicle stimulating hormone, and testosterone levels were determined $127 \mathrm{~d}$ postnatally and no significant differences from controls were observed in any of the treatment groups. Blood glactose-1-phosphate levels in animals receiving the $50 \%$ galactose diet were comparable to levels observed in human galactosemia. The resistance of the rat testis to a high galactose diet is consistent with the infrequency of testicular insufficiency in human galactosemia, and contrasts with the prenatal female gonadal sensitivity to galactose previously demonstrated in the rat and the high frequency of ovarian failure in human galactosemia.

\section{Abbreviations}

FSH, follicle stimulating hormone gal-1-p, galactose-1-phosphate LH, luteinizing hormone

With early diagnosis through newborn screening programs and institution of appropriate treatment, many patients with inherited metabolic disorders have survived with good long-term health and are now reaching childbearing age. Individuals with some inborn errors of metabolism have borne children (17), but their long-term fertility is largely unstudied.
Galactosemia, secondary to a deficiency in galactose-1-phosphate uridyl-transferase activity is inherited as an autosomal recessive trait and is characterized by mental retardation, cataracts, hepatosplenomegaly, and renal tubular dysfunction (19). The frequent association between this form of galactosemia and premature ovarian failure, even when a galactose-restricted diet is started early in infancy, is well documented $(9,11,21)$. Endocrinologic studies in affected women are consistent with hypergonadotropic hypogonadism. In contrast, testicular dysfunction is uncommon in galactosemia. Kaufman et al. (11) studied eight male patients, and found no evidence of hypothalamic, pituitary or testicular dysfunction. Steinman et al. (21), however, reported elevated levels of basal and stimulated FSH in three of their older patients (age, 21-24-yr-old), suggesting an abnormality in seminiferous tubular function.

Administration to rats of a $30-50 \%$ galactose diet is known to produce cataracts, liver abnormalities, and aminoaciduria resembling the human galactosemia syndrome $(18,20)$. We have shown previously, using this animal model, that offspring of rats fed a high galactose diet during pregnancy have significantly reduced numbers of oocytes (1). The data suggests that prenatal toxicity from galactose and/or its metabolites may contribute to the premature ovarian failure characteristic of human galactosemia. In this paper, we report, using the same animal model and similar experimental design, the effect of galactose treatment on male reproductive function.

\section{MATERIALS AND METHODS}

Galactose, gal-1-p, galactose dehydrogenase, and alkaline phosphate were purchased from Sigma Chemical Co. (St. Louis, MO), and a $50 \%$ galactose diet and corresponding regular rodent diet without galactose (NIH-07) from Zeigler Bros., Inc. (Gardners, PA). NIH-07 regular rodent diet consits of $24.5 \%$ protein, $5.2 \%$ fat, $3.7 \%$ fiber, and approximately $50 \%$ carbohydrate. The 
$50 \%$ galactose diet is prepared by mixing an equal weight of galactose and NIH-07 diet. Sprague-Dawley rats were obtained from the Veterinary Resources Branch, NIH.

Treatment of rats. Rats were housed in an animal room with a $14 \mathrm{~h}: 10 \mathrm{~h}$ day:night cycle and had free access to tap water. One group was exposed to galactose prenatally, that is pregnant rats received a $50 \%$ galactose diet ad libitum at various times during pregnancy: from d 1 postconception to gestational d 9 , d 9 to 14, d 15 to 20 , or during the entire gestational period. Another group was exposed to galactose only postnatally: the diet was given to lactating mothers at birth and continued until weaning at $27 \mathrm{~d}$ of age. After weaning, the pups were separated from the mothers and received the $50 \%$ galactose diet until $5 \mathrm{wk}$ of age. In addition, a group of rats was treated with galactose both prenatally and postnatally, from $\mathrm{d} 1$ postconception until $5 \mathrm{wk}$ of age. This group is not discussed further because prenatal plus postnatal galactose treatment was very toxic and no male offspring survived for study.

Control animals received a normal diet instead of the high galactose diet. As an additional control, rats were pair fed by food weight to rats receiving the galactose diet for the entire period of gestation.

All offspring were weaned $27 \mathrm{~d}$ after birth. Male and female rats were grouped in separate cages. Body and testicular weights of the offspring were determined at the indicated times.

Assay of galactose and gal-1-p. Galactose and gal-1-p levels were determined by a fluorometric method (6) on whole blood or whole amniotic fluid (including amniotic and exfoliated fetal cells) samples from animals maintained on the galactose or control diet for at least $4 \mathrm{~d}$. Fetal blood and amniotic fluids samples were assayed by pooling material from five individual fetuses.

Testicular histology. Testes were fixed in Bouin's medium for $24 \mathrm{~h}$, placed in $70 \%$ ethanol, processed and embedded in paraffin, and sections stained with hematoxylin-eosin. Seminiferous tubular diameter in testes of adult rats was evaluated at $66 \mathrm{~d}$ and $127 \mathrm{~d}$ using a Zeiss microscope (final magnification, $\times 100$ ) with the aid of an eyepiece micrometer. Thirty randomly selected circular cross sections per slide were counted. Slides were coded and during analysis the observer was not aware of specimen origin.

Radioimmunoassay of LH/FSH and testosterone. $\mathrm{LH}$ and FSH were assayed by using the NIADDK double-antibody radioimmunoassay kits with NIADDK-rat-LH-RPI and NIADDK-rat-FSH-RPI as the standards. Testosterone was assayed by the technique of Dufau et al. (4).

Statistical analysis. Group comparisons were made with Student's $t$ test for unpaired data.

\section{RESULTS}

Weight. When pregnant rats were treated with galactose for the entire period of gestation, there was a large $(\sim 30 \%)$ decrease in mean fetal body weight near term (Table 1). The group exposed to galactose only toward the end of pregnancy (d 15 postconception to d 20) also showed a significant but smaller decrease of fetal body weight. At birth the galactose diet was changed to a control diet and body weight again measured at weaning (27-d-old). The pups previously exposed to galactose showed catch-up growth and actually weighed more, on average, than the control or pair fed animals at weaning. The same trend persisted until adult life (66-d-old), and was significnt in the groups treated with galactose for first $10 \mathrm{~d}$ of gestation or for the entire period of gestation. By $127 \mathrm{~d}$ of age, the difference in body weights became smaller and statistically insignificant.

In the postnatal galactose treatment group, mean body weight was reduced to $45 \%$ of control at weaning. With cessation of galactose treatment at $35 \mathrm{~d}$ of age, mean body weight gradually increased and no significant differences in weight between control and treated groups were found at 66 or $127 \mathrm{~d}$ of age. These data

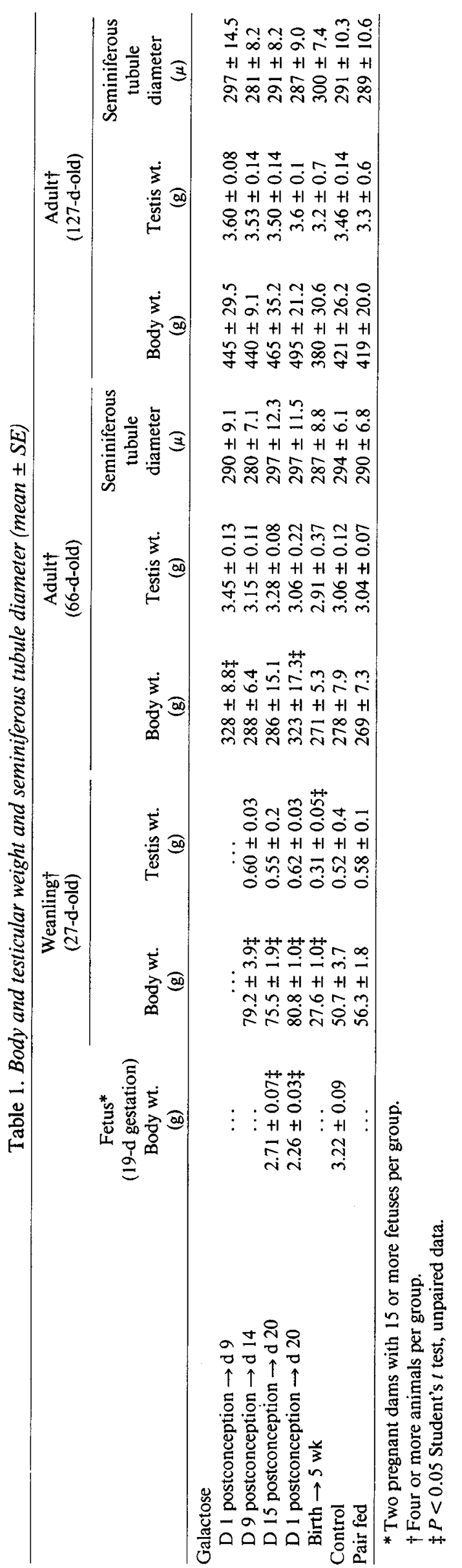


Table 2. Serum luteinizing hormone ( $L H)$, follicle stimulating hormone (FSH), and testosterone concentrations (mean $\pm S E$ )

\begin{tabular}{|c|c|c|c|}
\hline . & $\begin{array}{c}\text { LH } \\
(\mathrm{ng} / \mathrm{ml})\end{array}$ & $\begin{array}{c}\text { FSH } \\
(\mathrm{ng} / \mathrm{ml})\end{array}$ & $\begin{array}{c}\text { Testosterone } \\
(\mathrm{ng} / \mathrm{ml})\end{array}$ \\
\hline \multicolumn{4}{|l|}{ Galactose } \\
\hline D 1 postconception $\rightarrow$ d 9 & $24.1 \pm 8.8$ & $395 \pm 73.0$ & $242 \pm 12.3$ \\
\hline D 15 postconception $\rightarrow$ d 20 & $29.8 \pm 3.8$ & $295 \pm 19.3$ & $249 \pm 48.6$ \\
\hline D 1 postconception $\rightarrow \mathrm{d} 20$ & $34.4 \pm 7.3$ & $307 \pm 26.6$ & $632 \pm 153^{*}$ \\
\hline Birth $\rightarrow 5$ wk & $32.0 \pm 10.1$ & $320 \pm 40.1$ & $290 \pm 40.3$ \\
\hline
\end{tabular}

* Includes one value of $937, P<0.05$ when compared with control group and $P>0.1$ compared with pair fed group.

suggest that the reduction of body weight while animals receive galactose is temporary and reversible.

There were no significant differences in mean testicular weight between the control and galactose-treated groups except for those pups fed a $50 \%$ galactose diet postnatally. In this group, a $47 \%$ reduction of testicular weight was observed at weaning and body weight showed a $55 \%$ reduction. When the galactose diet was discontinued, both mean body and testicular weights returned to normal.

Testicular histology and seminiferous tubular diameter. Testicular histology and seminiferous tubular diameter were evaluated in testes of rats at 66 and $127 \mathrm{~d}$ of age. We extended our observations to 127-d-old rats because of the report (21) suggesting possible late testicular insufficiency in human galactosemia. The mean seminiferous tubular diameter in the galactose-treated groups did not differ significantly from the control or pair fed groups. Testicular histology, assessed by independent evaluation by two of the authors (Y.T.C. and D.R.M.), also did not differ between treatment and control groups.

Serum gonadotropin and testosterone concentrations. Serum $\mathrm{LH}, \mathrm{FSH}$, and testosterone levels were measured in the 127-dold animals (Table 2). There were no significant differences between control and treated groups in LH or FSH concentrations. Including one value of 937 (Table 2), the mean serum testosterone level in the offspring of rats treated with galactose during the entire period of gestation was significantly elevated when compared with the control; however, this difference was not significant when comparison was made to the pair fed group.

Galactose and gal-1-P levels. Table 3 shows the representative galactose and gal-1-P levels in whole blood and whole amniotic fluid (which includes amniotic and exfoliated fetal cells) samples from animals maintained on high galactose or control diets for at least $4 \mathrm{~d}$. In general, fetal blood levels of galactose and gal-1$P$ were slightly higher during galactose treatment than the cor-

Table 3. Representative galactose and galactose-1-phosphate (gal-1-p) level, (mean $\pm S E)^{*}$

\begin{tabular}{lcc}
\hline & $\begin{array}{c}\text { Galactose } \\
(\mathrm{mg} / \mathrm{dl})\end{array}$ & $\begin{array}{c}\text { Gal-1-P } \\
(\mathrm{mg} / \mathrm{dl})\end{array}$ \\
\hline $\begin{array}{l}\text { Prenatal } \\
\text { Mothers (4) } \dagger\end{array}$ & $357 \pm 56.4$ & $14 \pm 5.0$ \\
$\quad$ Amniotic fluid $\ddagger(20)$ & $416 \pm 37.2$ & $18 \pm 7.1$ \\
$\quad$ Fetuses (20) & $385 \pm 79.7$ & $15 \pm 7.1$ \\
Postnatal & & \\
$\quad$ Before weaning & & \\
$\quad$ Mother (3) & $44 \pm 13.5$ & $2.0 \pm 0.7$ \\
$\quad$ Pups (8) & $35 \pm 11.1$ & $1.8 \pm 0.4$ \\
$\quad$ After weaning, pups (6) & $420 \pm 107.8$ & $\ldots$ \\
Control (10) & $<1.5$ & $<1.0$ \\
\hline
\end{tabular}

* Part of the data in this table was previously published (1).

$\dagger($ ), number animals; each point is the average of duplicate determinations: for determination of amniotic fluid and fetuses, five samples were pooled and four separate pools were analyzed.

$\ddagger$ Includes amniotic and fetal cells. responding maternal concentrations, and amniotic fluid levels tended to be even higher than the corresponding fetal and maternal concentrations. The high concentration of gal-1-P in amniotic fluids may have resulted from the presence of amniotic and fetal cells in our samples. Lactating mothers and their pups had lower levels of blood galactose during galactose exposure than did pregnant dams, their fetuses, and those pups maintained on galactose beyond weaning. Control animals had blood or amniotic fluid galactose and gal-1-P concentrations below the level of detection in this assay. The blood gal-1-P levels in rats treated with the high galactose diet were comparable to levels observed in human galactosemia.

\section{DISCUSSION}

In this study, exposure of rats to galactose for various periods during gestation, or postnatally to nursing mothers until pups were $5 \mathrm{wk}$ of age, produced no significant alterations in testicular weight, seminiferous tubular diameter, microscopic appearance of the testis, or serum LH, FSH, and testosterone levels compared with pair fed animals when the offspring were adult (66 and/or $127 \mathrm{~d})$. Whether or not the temporary decrease in testicular weight noted at the time of weaning in the group exposed to galactose postnatally through their nursing mothers is due to a selective galactose effect on the testis remains to be determined. Atrophy of seminiferous tubules and varying degrees of arrest of sperm maturation have been previously reported in rats receiving of a $70 \%$ galactose diet (3).

We have shown previously, using the same animal model and similar experimental design, that when pregnant rats were fed a $50 \%$ galactose diet there was a striking reduction in oocyte number in prenatally exposed offspring (1). The most prominent effects on oocyte number were noted after galactose exposure during the pre-meiotic stage of oogenesis. These results contrast sharply with the apparant lack of a corresponding effect of galactose or its metabolites on the testes. The comparative resistance of the prenatal or postnatal male gonad to a high galactose diet is consonant with the apparent infrequency of testicular insufficiency in human galactosemia.

Both this study and the previous study on ovarian toxicity (1) have shown a similar large decrease $(\sim 30 \%)$ in mean fetal body weight at term when pregnant rats were fed a $50 \%$ galactose diet. Human galactosemia, in contrast, showed a smaller (8.6-12\%) but significant reduction of mean birth weight in galactosemic children compared with their unaffected siblings $(8)$. The difference in the degree of intrauterine growth retardation is probably not due to protein-calorie malnutrition created by the $50 \%$ galactose diet. The galactose diet employed in our studies contains $12.25 \%$ protein, which meets the basic protein requirement (12\%) for pregnant rats (15). Rats fed the galactose diet actually eat more than control rats. It should be noted, however, that the $50 \%$ galactose diet was prepared by mixing equal weights of galactose and control diet. Therefore the control and experimental diet in our study do not have the same nutrient composition. A study by Haworth et al. (7), using isocalorie diets, has demonstrated that rats fed a $40 \%$ galactose diet were not malnour- 
ished and the net caloric intake was similar to that of control rats. Perhaps the larger degree of growth retardation in rats results from exposure to a high galactose concentration during gestation. Human galactosemic fetuses, on the other hand, do not accumulate high levels of galactose because of rapid maternal clearance.

A similar experiment in mice was performed recently by us (unpublished data). Mice showed the same degree of intrauterine growth retardation, but in contrast to rats, no ovarian toxicity was noted. Mice are known to have very low levels of aldose reductase activity and do not develop cataracts when fed a high galactose diet (23). Our data suggests that the growth retardation with galactose treatment is not always associated with ovarian toxicity.

Prenatal ovarian toxicity or adverse effect on the female reproductive tract with little corresponding testicular toxicity is not without precedent. Treatment of pregnant mice with 6-mercaptopurine produces much greater reproductive impairment in the female when compared with the male offspring (16). Also, women treated prenataly with diethylstilbestrol have a significantly higher incidence of reproductive organ abnormalities in female versus male offspring (14). The formation of new germ cells by the mitotic activity of oogonia is completed in the rat before or shortly after birth. Once oogonial mitotic divisions have ceased, the ovary is unable to compensate for any chemical or radiation damage by regenerating new germ cells. In contrast, spermatogonia proliferate continuously throughout adult life, and the ability to repopulate the testis after injury has been well documented $(5,13)$.

A number of studies have shown that offspring of mothers who were underfed throughout pregnancy have permanently reduced body weight $(2,12,22)$. Jones and Friedman (10), however, observed that after weaning the male, but not female, offspring of rats underfed during the first 2 wk of gestation had greater weight gain than controls. We have observed, at weaning and in young adult, an analogous increase in the body weight of offspring of rats exposed to galactose prenatally. Female offspring in our study also showed the same weight increase at weaning (data not shown). It would be interesting to study the change of body composition, such as the number and size of adipocytes, in galactose-treated animals.

\section{REFERENCES AND NOTES}

1. Chen, Y. T., Mattison, D. R., Feigenbaum, L., Fukui, H., and Schulman, J. D.: Reduction in oocyte number following prenatal exposure to a diet high in galactose. Science, 214: 1145, (1981).

2. Chow, B. F. and Lee, C. J.: Effect of dietary restriction of pregnant rats on body weight gain of the offspring. J. Nutr., 82: 10 (1964).
3. Craig, J. M. and Maddock, C. E.: Observation of nature of galactose toxicity in rats. A.M.A. Arch. Pathol., 55:118, (1953).

4. Dufau, M. L., Catt, K. J., Tsuruhara, T., and Ryan, D.: Radioimmunoassay of plasma testosterone. Clin. Chim. Acta, 37: 109 (1972).

5. Ellis, L. C.: Radiation effect. In: A. D. Johnson, W. R. Gorres, and N. C. Vandermark: The Testis, Influencing Factors, Vol. III, p. 335 (Academic Press, New York, 1970).

6. Frazier, D. H., Cozart, W. S., and Summer, G. K.: Analysis of galactose-1-PO and galactose in blood by a new microfluorometric method. Biochem. Med. 20: 344, (1978).

7. Haworth, J. C., Ford, J. D., and Younoszai, M. K.: Effect of galactose toxicity on growth of the rat fetus and brain. Pediatr. Res., 3: 441 (1969).

8. Hsia, Y. Y. and Walker, F. A.: Variability in the clinical manifestation of galactosemia. J. Pediatr., 59: 872 (1961).

9. Hoefnagel, D., Wurster-Hili, D., and Child, E. L.: Ovarian failure in galactosemia. Lancet, 2: 1197 (1979).

10. Jones, A. P. and Friedman, M. I.: Obesity and adipocyte abnormalities in offspring of rats undernourished during pregnancy. Science, 215: 1518 (1982).

11. Kaufman, F. R., Kogut, M. D., Donnell, G. N., Goebelsmann, U., March, C., , and Koch, R.: Hypergonadotropic hypogonadism in female patients with galactosemia. New Engl. J. Med., 304: 994 (1981).

12. Knittle, J. L. and Hirsch, J.: Effect of early nutrition on the development of rat epididymal fat pads: cellularity and metabolism. J. Clin. Invest., 47: 2091 (1968).

13. Mardl, A. M.: The radiosensitivity of germ cells. Biol. Rev., 39: 288 (1964).

14. Mattison, D. R.: Drug, xenobiotics, and the adolescent: Implication for reproduction. In: L. F. Soyka and G. P. Redmond: Drug Metabolism in the Immature Human. p. 129 (Raven Press, New York, 1981).

15. Nutrient requirements of laboratory animals. National Research Council National Academy of Sciences, Washington, D.C. 1978.

16. Reimers, T. J., Sluss, P. M., Goodman, J., and Seidel, G. E.: Bigenerational effects of 6-mercaptopurine on reproduction in mice. Biol. Reprod., 22: 367 (1980).

17. Schulman, J. D. and Simpson, J. L.: Ed. Genetic Diseases in Pregnancy. (Academic Press, New York, 1981).

18. Segal, S. and Bernstein, $\mathrm{H}$.: Observation on cataract formation in the newborn offspring of rats fed a high-galactose diet. J. Pediat., 62: 363 (1963).

19. Segal, S.: Disorders of galactose metabolism. In: J. B. Stanbury, J. B. Wyngaarden, and D. S. Fredrickson: The Metabolic Basis of Inherited Disease. p. 160 (McGraw-Hill Book Co., New York, 1978).

20. Spatz, M. and Segal, S.: Transplacental galactose toxicity in rats. J. Pediatr., 67: $438(1965)$.

21. Steinman, B., Gitzelmann, R., and Zachmann, M.: Galactosemia: hypergonadotropic hypogonadism found already in prepubertal girls but only in adult males. Eur. J. Pediatr., 135: 337 (1981).

22. Tulp, O. L., Tyzhir, R. S., Morse, S. G., and Horton, E. S.: Effect of prenatal protein deprivation and subsequent rehabilitation of adipose tissue development in rats. Nutr. Rep. Int., 22: 135 (1980).

23. Varma, S. D. and Kinoshita, J. H.: The absence of cataracts in mice with congenital hyperglycemia. Exp. Eye Res., 19: 577 (1974).

24. the expert secretarial assistance of Ms. Debbe Kirk and Linda Hamilton is greatly appreciated.

25. Portions of this work were presented at the annual meeting of the American Pediatric Society and the Society for Pediatric Research, Washington, D.C., May $10-13,1982$.

26. Requests for reprints should be addressed to: Dr. Y. T. Chen, Pediatric Genetics and Metabolism, Duke University Medical Center, Durham, NC 27710.

27. Received for publication July 2, 1982 .

28. Accepted for publication June 17, 1983. 